\title{
THE RADIOLOGICAL ANALYSIS OF THE EFFECTS OF RALOXIFENE, NITRIC-OXIDE AND ESTROGEN ON SCOLIOSIS: A BIPEDAL C57BL6 MICE MODEL
}

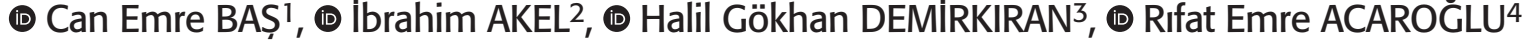 \\ ${ }^{1}$ University of Health Sciences Turkey, Dışkapı Training and Research Hospital, Clinic of Orthopedics and Traumatology, Ankara, Turkey \\ ${ }^{2}$ Kent Hospital, Clinic of Orthopedics and Traumatology, Izmir, Turkey \\ ${ }^{3}$ Hacettepe University Medicine Faculty, Department of Orthopedics and Traumatology, Ankara, Turkey \\ ${ }^{4}$ Ankara Spine Center, Department of Orthopedics and Traumatology, Ankara, Turkey
}

Objective: Raloxifene (RLX), estrogen and nitric - oxide (NO) medications were showed to be related to scoliosis but the complex mechanism is not solved yet. Since these drugs are safe to use in humans, prevention and non-surgical treatment of scoliosis may be achieved with these drugs. We aimed to investigate the effects of estrogen, RLX and NO on scoliosis progression, bone mineral density and sagittal plan deformities. Materials and Methods: One hundred and fifty-two C57BL6 mice were grouped into bipedal Estrogen, bipedal RLX, bipedal NO, bipedal control and quadripedal control groups. All of the animals' forelimbs and tails were amputated, except quadripedal group ( $\mathrm{n}=28$ ), and followed for 5 weeks. Estrogen, NO and RLX groups received orally administered Estrogen, NO and RLX after 5th week for 35 weeks. Anteroposterior and lateral X-ray imaging were done at 5th, 20th and 40th weeks and bone mineral density measurements were done at 20th and 40th weeks.

Results: There was no significant difference in mean Cobb angles between the groups at fifth, 20th and 40th weeks $(p=0.917, p=0.066, p=0.562$, respectively). There was a significant increase in mean Cobb angles in quadripedal group between 20th and 40th week. There was no significant difference between the groups based on scoliosis incidence at fifth, 20th weeks ( $p=1.000, p=0.132$, respectively). However when the progression of the scoliosis was investigated, there was a tendency to decrease in scoliosis progression of RLX group when compared to other groups. Although there was a tendency to decrease in thoracic kyphosis angles, and pelvic incidence between $20^{\text {th }}$ week and $40^{\text {th }}$ week in all groups, no statistical difference was found. Spinosacral angles had significant increase between $20^{\text {th }}$ week and $40^{\text {th }}$ week in all groups except quadripedal group. There was a significant increase of bone mineral density in RLX group $(p=0.041)$.

Conclusion: RLX may decrease scoliosis progression in C57BL/6 mice model and increase bone mineral density. Unlike previous studies, quadripedal mice group had a tendency to progress scoliosis between 20th and 40th weeks.

Keywords: Scoliosis, raloxifene, nitric-oxide, estrogene, C57Bl6 mice, sagittal plan deformities

\section{INTRODUCTION}

Adolescent idiopathic scoliosis (AIS) is a spine deformity due to unknown causes in which preventive treatments does not exist so usually patients with this disease require intensive brace therapy or surgery ${ }^{1}$. Possible etiological mechanisms of AIS have been investigated but the factors leading to AIS are not solved entirely. . $3,4^{3}$ As an experimental model, pineolectomy of the chicken was shown to produce scoliosis in previous studies $.5,6$ With further studies, scoliotic deformity was produced in rats when they were forced to survive in a bipedal posture by amputation of the forelimbs and tails. ${ }^{7}$ C57BL6 mice, inbreed species without melatonin synthesis, were also used for the animal scoliosis model so that pinealectomy was not needed and when they gained bipedal posture via amputations of their forelimbs and tails, scoliosis can be seen at 20 weeks. ${ }^{8}$ Based on these studies, a clinical study showed that children with progressive scoliosis have lower blood melatonin levels when compared with children without scoliosis. ${ }^{9}$ During the investigation of the effects of melatonin, Acaroglu et al. found that there was no difference in the levels of melatonin but calmodulin levels in the paravertebral muscles on the convex side of the scoliotic patients were found to be higher compared to the control group. ${ }^{10}$ Further studies showed that Calmodulin antagonism is beneficial for prevention of the scoliosis progression. ${ }^{2,11,12,13}$ Calmodulin antagonism with a Selective Estrogen Receptor Modulator (SERM) like tamoxifene showed that tamoxifene decreases the rate of progression of the scoliosis. ${ }^{2}$ Raloxifene (RLX) is another SERM that is used for the 
prevention and treatment of osteoporosis in postmenopausal women. ${ }^{14}$ In a study with ovariectomised mice, it was shown that RLX was effective in preserving the bone microstructure. ${ }^{15}$ In another study, RLX and tamoxifene treatment of bipedal C57Bl6 mice showed that RLX is as effective as tamoxifene. ${ }^{13}$

Estrogen is thought to be an etiologic factor involving in AIS pathogenesis ${ }^{16}$. Experiments with bipedal rat models demonstrated that estrogen promotes the onset and development of the idiopathic scoliosis ${ }^{17}$. Despite the contrary publications ${ }^{18,19}$, previous studies performed on girls with AIS showed that there may be differences in serum estradiol concentrations and determination of the estradiol levels may be useful in detecting the spinal pathologies in AIS20,21.

Nitric oxide (NO) is another molecule that may be involved in the etiology of the idiopathic scoliosis. NO levels on the concave side of the paraspinal muscles of the idiopathic scoliosis patients was found higher compared to the convex side ${ }^{22,23}$.

Due to these complex findings in the etiology of the idiopathic scoliosis, further studies are required about the effects of the drugs in the scoliosis progression. We aimed to investigate the effects of RLX, NO and Estrogen on scoliosis incidence and progression at a scoliotic mice model.

\section{MATERIALS AND METHODS}

The study was conducted in an animal research laboratory with a total of 180 melatonin deficient, 3 weeks old, 15 grams weighted, C57BL6/NCrl mice after obtaining local ethics committee approval (Hacettepe University Animal Experimentations Ethics Board, date: 12.07.2011, decision no: B.30.2.HAC.0.05.06.00/59). All subjects', except quadripedal group ( $n=28$ ), forelimbs and tails were amputated and rendered bipedal under general anesthesia to obtain scoliosis model as previously described ${ }^{8}$. Twenty-two mice were dead during amputation process.All mice receive pain-control and antibiotics prophylaxis following surgical procedure. Remaining 158 mice were followed for 5 weeks without an intervention. Six mice were dead during 5-week follow-up. At the fifth week follow-up, 152 mice were alive and they were randomly separated into 5 groups. There were 28 mice in quadripedal group (group 1), 42 mice in bipedal group (group 2), 27 mice in bipedal estrogen group (group 3), 29 mice in bipedal RLX group (group 4), and 26 mice in bipedal NO group (group 5). For the baseline evaluation, anteroposterior and lateral spinal radiographs were obtained from ten mice in quadripedal group and fourteen mice in bipedal group and following radiographic evaluation, they were sacrificed for histological evaluation. Medications were given to subjects starting from fifth week and administered as follows: Mice in group $1(n=18)$ and group $2(n=28)$ received no medication. Mice in group $3(n=27)$ received estrogen $(0.5 \mathrm{mg} /$ $\mathrm{kg} /$ day). Mice in group $4(\mathrm{n}=28)$ received $\mathrm{RLX}(1 \mathrm{ml} / \mathrm{kg} /$ day). Mice in group $5(\mathrm{n}=26)$ received NO $(0.2 \mathrm{mg} / \mathrm{kg} /$ day $)$. All medication was prepared by smashing the tablet form of the drugs and dissolving in the distilled water. All medication was given to subjects via oral administration through drinking water. Doses of medications were adjusted based on previous literature ${ }^{13}$. Medications were continued by daily basis for 40 weeks.

Twenty-seven mice ( 1 in quadripedal group, 2 in bipedal control group, 15 in estrogen group, 9 in NO group) were dead between fifth week and 20th week follow-up. Anteroposterior and lateral spinal radiographs were taken, pelvic and spinal bone mineral density were measured in all groups at 20th week follow-up; and then, 56 mice ( 8 in quadripedal group, 13 in bipedal group, 7 in estrogen group, 13 in RLX group, 8 in NO group) were sacrificed for histological evaluation. None of the mice were dead between 20th week and 40th week follow-up. Remaining mice were initially evaluated with anteroposterior and lateral spinal radiographs and bone mineral density (pelvic and spinal), then sacrificed for histological examination. All the mice were kept in $22^{\circ} \mathrm{C} \pm 2$ environmental conditions with 12 hours light / darkness cycles. The position of the water bottle and nutrition was set in a way that mice had to stand-up over two feet to reach them.

Radiographs and bone mineral density measurements were obtained under ether anesthesia. Coronal plane deformity analysis was performed based on the previous study ${ }^{13}$. Sagital plane deformity analysis was made based on thoracic kyphosis, spinosacral angles, and pelvic incidence ${ }^{22}$. Bone mineral density values were given with $\mathrm{g} / \mathrm{cm}^{2}$. Subjects having a Cobb angle above 5 degrees considered as being scoliosis. An example of anteroposterior and lateral spinal radiograph of a mouse is shown in figure 1.

\section{Statistical Analysis}

The normality analysis of the data was performed with Kolmogorov Smirnov test. The mean of the variables was evaluated with Kruskal-Wallis test, categorical variables were compared with chi-square test. Continuous variables are presented as mean \pm SD, whereas categorical variables are given as frequencies. Analyses of the data were performed using the IBM SPSS Statistics 23.0 (IBM Corporation, Armonk, NY, USA) program. The results were considered statistically significant when the $p$-value was $<0.05$.
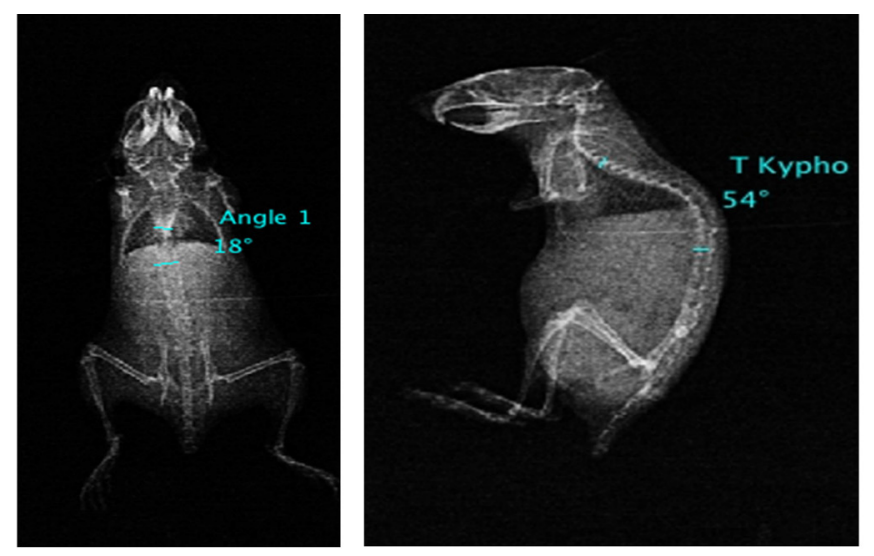

Figure 1. An anteroposterior and lateral spinal radiograph of a bipedal mouse 


\section{RESULTS}

Mean Cobb angles at fifth, 20th and 40th weeks were given in Table 1. There was no significant difference in mean Cobb angles between the groups at fifth, 20th and 40th weeks ( $p=0.917, p=0.066, p=0.562$, respectively). There was a significant increase in mean Cobb angles in quadripedal group between 20th and 40th week (Figure 2).

The incidences of scoliosis according the weeks were given in Figure 3. There was no significant difference between the groups based on scoliosis incidence at fifth, 20th weeks $(p=1.000, p=0.132$, respectively). Due to the small number of subjects at 40th week, no statistical comparison was performed. (Table 2)
Mean thoracic kyphosis angles, spinosacral angles, pelvic incidence according to the weeks are given in Table 3. Although there was a tendency to decrease in thoracic kyphosis angles (figure 4), and pelvic incidence (figure 5) between 20th week and 40th week in all groups, no statistical difference was found. Spinosacral angles had significant increase between 20th week and 40th week in all groups except quadripedal group (figure $6)$.

The course of bone mineral density between 20th week and 40th week are shown in Table 4. There was a significant increase in RLX group ( $p=0.041)$. (figure 7)

The results of the histological evaluation of the sacrified mice did not show any significant finding.

Table 1. Mean cobb angles at 5th, 20th and 40th weeks

\begin{tabular}{|c|c|c|c|c|c|c|}
\hline & $5^{\text {th }}$ week & & $20^{\text {th }}$ week & & $40^{\text {th }}$ week & \\
\hline Bipedal group & $12 \pm 8.1$ & \multirow{4}{*}{$P=0.917$} & $11.9 \pm 9.0$ & \multirow{4}{*}{$P=0.066$} & $16.5 \pm 12.8$ & \multirow{4}{*}{$P=0.562$} \\
\hline Quadripedal group & $9 \pm 5.5$ & & $18.8 \pm 10.4$ & & $23.3 \pm 10.2$ & \\
\hline Raloxifen group & - & & $12.4 \pm 7.3$ & & $18.7 \pm 16.1$ & \\
\hline Nitric oxide group & - & & $17.3 \pm 14.4$ & & $18.4 \pm 13.0$ & \\
\hline
\end{tabular}

Table 2. Scoliosis incidences at $5^{\text {th }}, 20^{\text {th }}$ and $40^{\text {th }}$ weeks

\begin{tabular}{|c|c|c|c|c|c|c|}
\hline & $5^{\text {th }}$ week & & $20^{\text {th }}$ week & & $40^{\text {th }}$ week & \\
\hline Bipedal group & $41.6 \%$ & \multirow{4}{*}{$P=0.528$} & $64.2 \%$ & \multirow{4}{*}{$P=0.132$} & $66.6 \%$ & \multirow{4}{*}{ N/A } \\
\hline Quadripedal group & $55.6 \%$ & & $79.3 \%$ & & $68.7 \%$ & \\
\hline Raloxifen group & - & & $64.7 \%$ & & $77.8 \%$ & \\
\hline Nitric oxide group & - & & $88.2 \%$ & & $100 \%$ & \\
\hline
\end{tabular}

Table 3. Mean thoracic kyphosis, spinosacral angle, pelvic incidence at $5^{\text {th }}, 20^{\text {th }}$ and $40^{\text {th }}$ weeks

\begin{tabular}{|c|c|c|c|c|c|c|}
\hline $\begin{array}{l}\text { Thoracic kyphosis Spinosacral } \\
\text { angle } \\
\text { Pelvic incidence }\end{array}$ & $5^{\text {th }}$ week & & $20^{\text {th }}$ week & & $40^{\text {th }}$ week & \\
\hline Bipedal group & $\begin{array}{l}56.8 \pm 12.7 \\
82.2 \pm 32.7 \\
14.3 \pm 7.1\end{array}$ & $P=1.000$ & $\begin{array}{l}48.5 \pm 14.0 \\
46.6 \pm 7.8 \\
15.4 \pm 8.0\end{array}$ & \multirow[b]{4}{*}{$\begin{array}{l}P=0.001 \\
P<0.001 \\
P=0.016\end{array}$} & $\begin{array}{l}45.5 \pm 8.4 \\
56.5 \pm 11.2 \\
12.3 \pm 9.2\end{array}$ & \multirow[b]{4}{*}{$\begin{array}{l}P=0.562 \\
P=0.523 \\
P=0.523\end{array}$} \\
\hline Quadripedal group & $\begin{array}{l}57.8 \pm 12.4 \\
78.1 \pm 19.3 \\
9.6 \pm 6.9\end{array}$ & $\begin{array}{l}P=0.346 \\
P=0.120\end{array}$ & $\begin{array}{l}45.8 \pm 12.3 \\
60.1 \pm 9.7 \\
20.8 \pm 4.9\end{array}$ & & $\begin{array}{l}44.6 \pm 8.8 \\
67.6 \pm 7.9 \\
16.9 \pm 5.4\end{array}$ & \\
\hline Estrogen group & & - & $\begin{array}{l}58.8 \pm 9.8 \\
47.1 \pm 8.8 \\
18.7 \pm 7.1\end{array}$ & & $\begin{array}{l}48.8 \pm 8.7 \\
57.3 \pm 7.5 \\
13.8 \pm 10.6\end{array}$ & \\
\hline Raloxifen group & & - & $\begin{array}{l}54.6 \pm 15.3 \\
42.8 \pm 9.9 \\
14.8 \pm 6.1\end{array}$ & & $\begin{array}{l}48.6 \pm 10.3 \\
59.8 \pm 12.0 \\
13.6 \pm 8.4\end{array}$ & \\
\hline
\end{tabular}




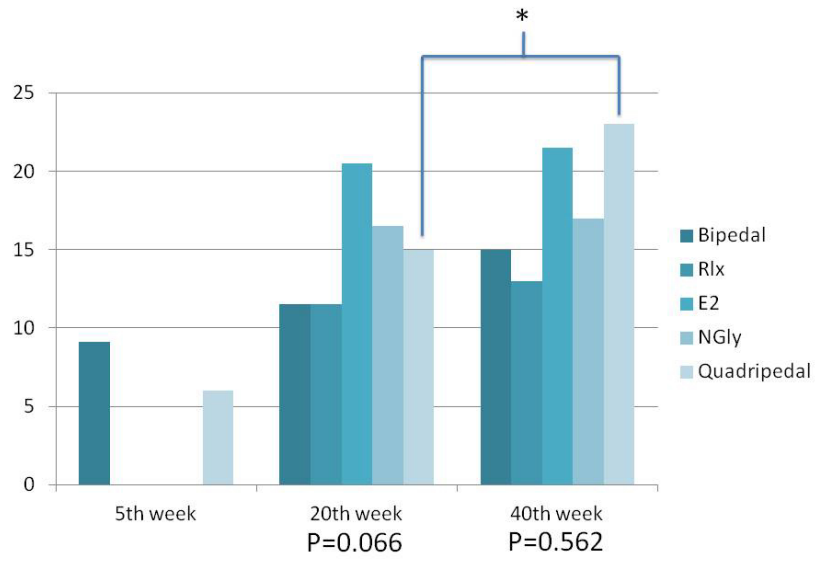

Figure 2. Mean Cobb angles in all groups at $5^{\text {th }}, 20^{\text {th }}$ and $40^{\text {th }}$ weeks. There was a significant increase in mean Cobb angles in quadripedal group between $20^{\text {th }}$ and $40^{\text {th }}$ week $(p=0.035)$

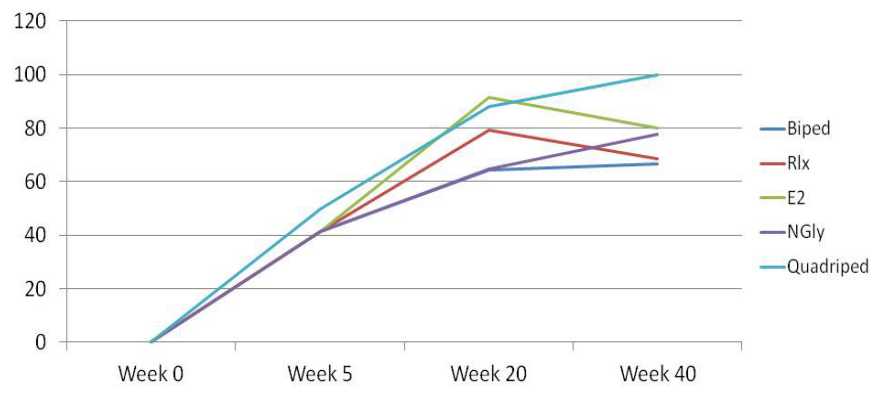

Figure 3. The incidences of scoliosis according to the weeks

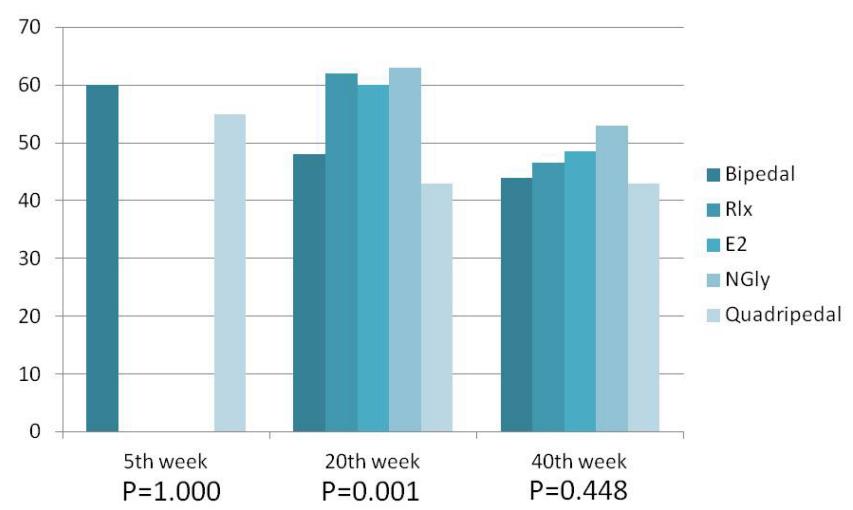

Figure 4. The mean of thoracic kyphosis angles in all groups at $5^{\text {th }}$, $20^{\text {th }}$ and $40^{\text {th }}$ weeks

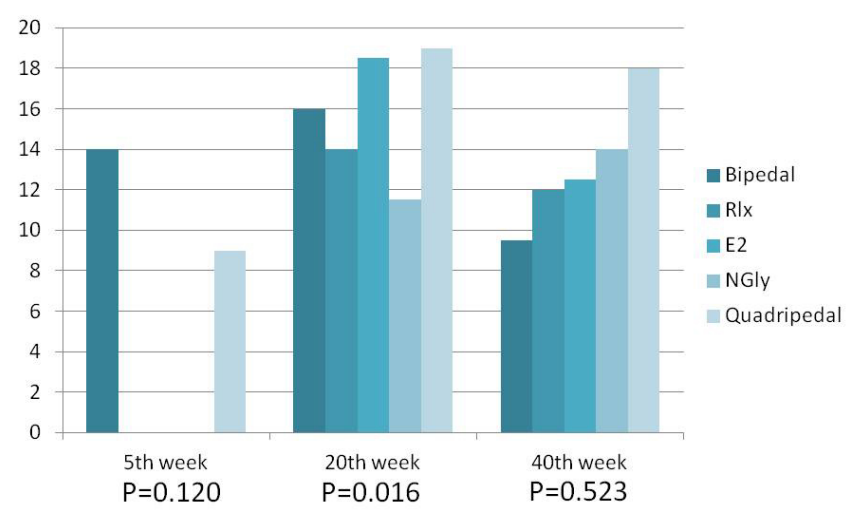

Figure 5. The mean of pelvic incidence angles in all groups at $5^{\text {th }}$, $20^{\text {th }}$ and $40^{\text {th }}$ weeks

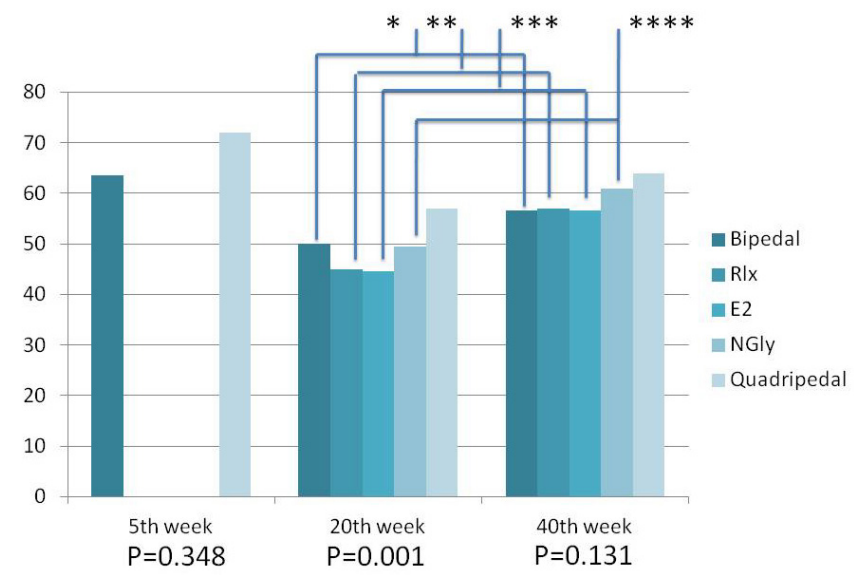

Figure 6 . The mean of spinosacral angles in all groups at $5^{\text {th }}, 20^{\text {th }}$ and $40^{\text {th }}$ weeks

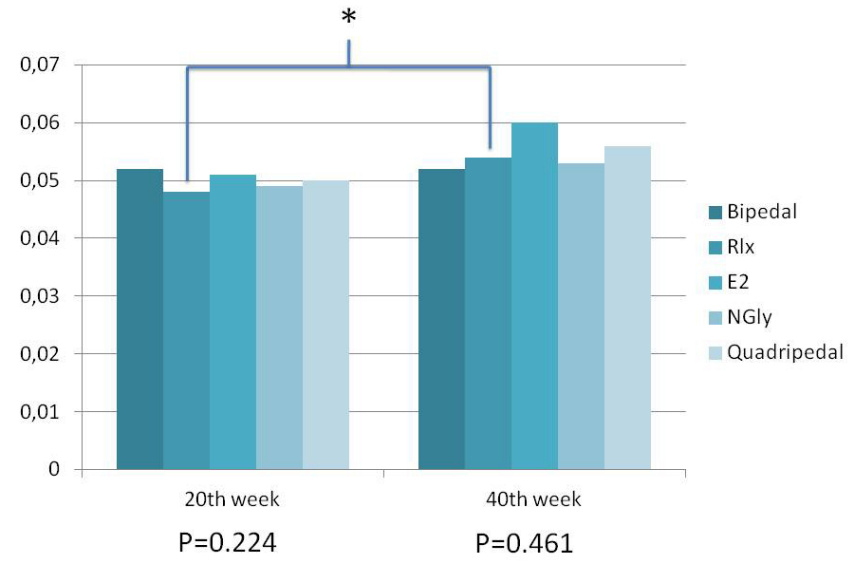

Figure 7. The mean of bone mineral density in all groups at $20^{\text {th }}$ and $40^{\text {th }}$ weeks 
Table 4. Mean pelvis bone density values at the 20th and 40th weeks

\begin{tabular}{|c|c|c|c|c|}
\hline & $20^{\text {th }}$ week & & $40^{\text {th }}$ week & \\
\hline Bipedal group & $0.051 \pm 0.005$ & \multirow{5}{*}{$P=0.224$} & $0.053 \pm 0.007$ & \multirow{5}{*}{$P=0.461$} \\
\hline Quadripedal group & $0.053 \pm 0.007$ & & $0.052 \pm 0.008$ & \\
\hline Estrogen group & $0.053 \pm 0.007$ & & $0.058 \pm 0.006$ & \\
\hline Raloxifen group & $0.049 \pm 0.007$ & & $0.053 \pm 0.009$ & \\
\hline Nitric oxide group & $0.048 \pm 0.006$ & & $0.051 \pm 0.006$ & \\
\hline
\end{tabular}

\section{DISCUSSION}

Our primary goal in this study was to investigate the effects of RLX (calmodulin antagonist), estrogen and NO in the etiology of scoliosis with C57BL6 mice model. Calmodulin is an important mediator of cellular calcium metabolism and calmodulin antagonism was found to decrease the incidence and magnitude of the scoliosis in the pinealectomized chicken ${ }^{25}$. Studies on C57BL/6 mice model, calmodulin antagonism with tamoxifen was successful at inhibiting the progression and decreasing the magnitude of curves ${ }^{2}$ and this finding was supported by further studies $^{11}$. Another selective estrogen modulator; RLX was also found to be as effective as Tamoxifen in decreasing the magnitude of the spinal deformities on C57BL/6 mice model ${ }^{12}$ and both RLX and Tamoxifen were found to be effective in the improving of the osteopenia and scoliotic deformity ${ }^{13}$. Our results demonstrated that at the $5^{\text {th }}, 20^{\text {th }}$, and $40^{\text {th }}$ week, there was no statistically significant difference in the mean Cobb angles in the groups. However, when the progression of the scoliosis was investigated, there was a tendency to decrease in scoliosis progression of RLX group when compared to other groups, which was consistent with the previous studies.12,13 But our results with RLX's inhibitory effect is not as powerful as previous studies. Also contrary to our hypothesis, estrogen and NO were not found to be effective in the treatment. RLX has multiple effects in the vertebra not only through Calmodulin receptors, but also with estrogen receptors leading to prevention of osteopenia. The reason of the inhibitory effect of RLX on progression of the scoliosis may be due to these complex functions unlike isolated effects of estrogen and NO donors. However, when the numbers of the animals in all groups were compared, there were small number of mice remaining in the estrogen and NO groups due to unexpected deaths during the study which may affect the result.

It is not clear if estrogen and selective estrogen receptor modifiers act through the calmodulin receptors to decrease the osteopenia. The association between osteopenia and scoliosis was showed in previous studies ${ }^{26,27}$ and animal models ${ }^{28}$. Treatment of osteopenia resulted in decreased curvatures in C57Bl6 mice models ${ }^{13,29}$, and in our study RLX group demonstrated increased bone mineral density which supported previous studies. RLX is clinically used in breast cancer and osteopenia treatment, but effect of RLX in scoliosis progress requires further evaluation.

Mouse and rat spine is being used as a mechanical model of the human ${ }^{17,30}$. But there are arguments about using quadripedal animal lumbar spines as a model of bipedal human spine. Quadripedal models, due to the absence of axial gravitation force, a mechanical asymmetry along the spine is required to initiate a scoliosis; on the other hand, bipedal models can mimic human posture and are under effect of similar forces due to gravity, which is thought to be a contributing factor to the development of scoliosis ${ }^{31}$. In quadripedal animals, spine is in the horizontal plane that the loads on vertebral bodies or discs are not on axial compression. In quadripedal group, contrary to previous studies ${ }^{8,24}$ there was a statistically significant increase in scoliosis incidence when the results in $20^{\text {th }}$ week and $40^{\text {th }}$ week are compared. This result may be supported with further studies and may show that bipedality is not mandatory in researches with C56BL/6 mice.-

During the growth, sagital profile of spine changes and scoliosis may develop due to either lateral asymmetry of the spine or a primary rotational problem ${ }^{24}$. Idiopathic scoliosis is a three dimensional deformity presenting with hypokyphosis in the sagittal plane ${ }^{28}$. The incidence of vertebral rotation and the degree of kyphoscoliosis was increased in bipedal rats following contralateral ilium tethering procedure ${ }^{32}$ and selective brain stem damage in quadripedal rats $^{33}$. Kyphoscoliosis was also seen in SHP2-deficient mice ${ }^{34}$ but we failed to find any investigation about hypokyphosis in scoliotic mice. It was thought that kyphosis may be a factor for in scoliosis progression 35 . In this study we aimed to investigate the sagittal plane analysis of the spine and pelvis based on these findings. There was a tendency to decrease in thoracic kyphosis, pelvic incidence in all groups but we were unable to show any statistically significant difference. However, there was a significant increase in spinosacral angle between $20^{\text {th }}$ and $40^{\text {th }}$ weeks in all groups except quadripedal group which may be due to adaptation to the bipedality.

Our study has some limitations and shortcomings. The number of the mice in each group was not equal due to deaths. And extension of the study to human may not be possible due to unknown effects of the estrogen, RLX and NO. However, with 
the utility of estrogen, RLX and NO could reveal the possible mechanisms of AIS. On the basis of the current study new medications for conservative treatment of AIS may be planned.

\section{CONCLUSION}

RLX may decrease scoliosis progression in C57BL/6 mice model and may increase bone-mineral density. Unlike previous studies, quadripedal mice group had a tendency to progress scoliosis between $20^{\text {th }}$ and $40^{\text {th }}$ weeks.

\section{Ethics}

Ethics Committee Approval: This study was approved by Hacettepe University Animal Experimentations Ethics Board (date: 12.07.2011, decision no: B.30.2.HAC.0.05.06.00/59).

Informed Consent: Experimental study.

Peer-review: Internally peer-reviewed.

\section{Authorship Contributions}

Concept: R.E.A., H.G.D., Design: R.E.A., H.G.D., Data Collection or Processing: C.E.B., H.G.D., Analysis or Interpretation: C.E.B., I.A., H.G.D., R.E.A., Literature Search: C.E.B., I.A.,

Writing: C.E.B., I.A., H.G.D.

Conflict of Interest: DePuy Synthes, Medtronic, AO Spine, Cotrel Foundation (REA).

Financial Disclosure: This study was conducted as a thesis of an author (Can Emre Baş) and was funded by Yves Cotrel Foundation.

\section{REFERENCES}

1. Zamecnik J, Krskova L, Hacek J, Stetkarova I, Krbec M. Etiopathogenesis of adolescent idiopathic scoliosis: Expression of melatonin receptors $1 \mathrm{~A} / 1 \mathrm{~B}$, calmodulin and estrogen receptor 2 in deep paravertebral muscles revisited. Mol Med Rep. 2016;14(6):5719-24.

2. Akel I, Demirkiran G, Alanay A, Karahan S, Marcucio R, Acaroglu E. The effect of calmodulin antagonists on scoliosis: bipedal C57BL/6 mice model. Eur Spine J. 2009;18(4):499-505.

3. Ahn UM, Ahn NU, Nallamshetty L, Buchowski JM, Rose PS, Miller NH, et al. The etiology of adolescent idiopathic scoliosis. Am J Orthop (Belle Mead NJ). 2002;31(7):387-95.

4. Lowe TG, Edgar M, Margulies JY, Miller NH, Raso V], Reinker KA, et al. Etiology of idiopathic scoliosis: current trends in research. J Bone Joint Surg Am. 2000;82(8):1157-68.

5. Machida $M$, Dubousset J, Imamura $\mathrm{Y}$, Iwaya T, Yamada T, Kimura J. Role of melatonin deficiency in the development of scoliosis in pinealectomised chickens. J Bone Joint Surg Br. 1995;77(1):134-8.

6. Machida M, Miyashita Y, Murai I, Dubousset J, Yamada T, Kimura J. Role of serotonin for scoliotic deformity in pinealectomized chicken. Spine (Phila Pa 1976). 1997;22(12):1297-301.

7. Machida M, Murai I, Miyashita Y, Dubousset J, Yamada T, Kimura J. Pathogenesis of idiopathic scoliosis. Experimental study in rats. Spine (Phila Pa 1976). 1999;24(19):1985-9.

8. Machida M, Dubousset J, Yamada T, Kimura J, Saito M, Shiraishi T, et al. Experimental scoliosis in melatonin-deficient C57BL/6] mice without pinealectomy. J Pineal Res. 2006;41(1):1-7

9. Machida M, Dubousset J, Imamura Y, Miyashita Y, Yamada T, Kimura J. Melatonin. A possible role in pathogenesis of adolescent idiopathic scoliosis. Spine (Phila Pa 1976). 1996;21(10):1147-52.

10. Acaroglu E, Akel I, Alanay A, Yazici M, Marcucio R. Comparison of the melatonin and calmodulin in paravertebral muscle and platelets of patients with or without adolescent idiopathic scoliosis. Spine (Phila Pa 1976). 2009;34(18):E659-63.
11. Wu JZ, Wu WH, He LJ, Ke QF, Huang L, Dai ZS, et al. Effect of Melatonin and Calmodulin in an Idiopathic Scoliosis Model. Biomed Res Int. 2016;2016:8460291.

12. Akel I, Demirkiran G, Olgun D, Tanrikulu S, Dede O, Marcucio $\mathrm{R}$ et al. Tamoxifen Versus Raloxifene For The Treatment Of Scoliosis: Bipedal C57bl/6 Mice Model. Orthopaedic Proceedings. 2012;94-B(SUPP_XXVII):52-.

13. Demirkiran G, Dede O, Yalcin N, Akel I, Marcucio R, Acaroglu E. Selective estrogen receptor modulation prevents scoliotic curve progression: radiologic and histomorphometric study on a bipedal C57Bl6 mice model. Eur Spine J. 2014;23(2):455-62.

14. Burshell AL, Song J, Dowsett SA, Mershon JL, Delmas PD, Secrest RJ et al. Relationship between bone mass, invasive breast cancer incidence and raloxifene therapy in postmenopausal women with low bone mass or osteoporosis. Current Medical Research and Opinion. 2008; 24(3): 807-813.

15. Cano A, Dapia S, Noguera I, Pineda B, Hermenegildo C, del Val R et al, Comparative effects of 17 -estradiol, raloxifene and genistein on bone 3D microarchitecture and volumetric bone mineral density in the ovariectomized mice. Osteoporos Int (2008) 19:793-800

16. Leboeuf D, Letellier K, Alos N, Edery P, Moldovan F. Do estrogens impact adolescent idiopathic scoliosis? Trends Endocrinol Metab. 2009;20(4):147-52.

17. Zheng S, Zhou H, Gao B, Li Y, Liao Z, Zhou T, et al. Estrogen promotes the onset and development of idiopathic scoliosis via disproportionate endochondral ossification of the anterior and posterior column in a bipedal rat model. Exp Mol Med. 2018;50(11):1-11.

18. Raczkowski JW. The concentrations of testosterone and estradio in girls with adolescent idiopathic scoliosis. Neuro Endocrinol Lett. 2007;28(3):302-4.

19. Sanders JO, Browne RH, McConnell SJ, Margraf SA, Cooney TE, Finegold DN. Maturity assessment and curve progression in girls with idiopathic scoliosis. J Bone Joint Surg Am. 2007;89(1):64-73.

20. Kulis A, Zarzycki D, Ja kiewicz J. Concentration of estradiol in girls with idiophatic scoliosis. Ortop Traumatol Rehabil. 2006;8(4):455-9.

21. Kulis A, Go dzialska A, Dr g J, Ja kiewicz J, Knapik-Czajka M, Lipik $\mathrm{E}$, et al. Participation of sex hormones in multifactorial pathogenesis of adolescent idiopathic scoliosis. Int Orthop. 2015;39(6):1227-36.

22. Zhao $Y$, Qiu GX. [Expression of calmodulin and $n N O S$ in the paraspinal muscles in idiopathic scoliosis]. Zhonghua Yi Xue Za Zhi. 2004;84(16):1358-61.

23. Zhao Y, Qiu GX. [Expression of neuronal nitric oxide synthase and inducible nitric oxide synthase in the erector spinal muscles in idiopathic scoliosis]. Zhongguo Yi Xue Ke Xue Yuan Xue Bao. 2004;26(4):451-4.

24. Machida M, Saito M, Dubousset J, Yamada T, Kimura J, Shibasaki K. Pathological mechanism of idiopathic scoliosis: experimental scoliosis in pinealectomized rats. Eur Spine J. 2005;14(9):843-8.

25. Akel I, Kocak O, Bozkurt G, Alanay A, Marcucio R, Acaroglu E. The effect of calmodulin antagonists on experimental scoliosis: a pinealectomized chicken model. Spine (Phila Pa 1976). 2009;34(6):533-8.

26. Cheng JC, Guo X, Sher AH. Persistent osteopenia in adolescent idiopathic scoliosis. A longitudinal follow up study. Spine (Phila Pa 1976). 1999;24(12):1218-22.

27. Cheng JC, Qin L, Cheung CS, Sher AH, Lee KM, Ng SW, et al. Generalized low areal and volumetric bone mineral density in adolescent idiopathic scoliosis. J Bone Miner Res. 2000;15(8):1587-95.

28. Dede O, Akel I, Demirkiran G, Yalcin N, Marcucio R, Acaroglu E. Is decreased bone mineral density associated with development of scoliosis? A bipedal osteopenic rat model. Scoliosis. 2011;6(1):24.

29. Tanabe H, Aota Y, Yamaguchi Y, Kaneko K, Imai S, Takahashi M, et al. Minodronate treatment improves low bone mass and reduces progressive thoracic scoliosis in a mouse model of adolescent idiopathic scoliosis. PLoS One. 2018;13(8):e0202165.

30. Zeng K, Zhang HQ, Chen Y, Gao Q. Estradiol via estrogen receptor beta inhibits chondrogenesis of mouse vertebral growth plate in vitro. Childs Nerv Syst. 2016;32(3):461-5. 
turkishspine

31. Bobyn JD, Little DG, Gray R, Schindeler A. Animal models of scoliosis. J Orthop Res. 2015;33(4):458-67.

32. Liu L, Zhu Y, Han X, Wu Y. The creation of scoliosis by scapula-tocontralateral ilium tethering procedure in bipedal rats: a kyphoscoliosis model. Spine (Phila Pa 1976). 2011;36(17):1340-9.

33. Barrios C, Arrotegui JI. Experimental kyphoscoliosis induced in rats by selective brain stem damage. Int Orthop. 1992;16(2):146-51.
34. Kim HK, Aruwajoye O, Sucato D, Richards BS, Feng GS, Chen D, et al. Induction of SHP2 deficiency in chondrocytes causes severe scoliosis and kyphosis in mice. Spine (Phila Pa 1976). 2013;38(21):E1307-12.

35. Crijns T], Stadhouder A, Smit TH. Restrained Differential Growth: The Initiating Event of Adolescent Idiopathic Scoliosis? Spine (Phila Pa 1976). 2017;42(12):E726-e32. 